\title{
Microencapsulação de probióticos por gelificação iônica externa utilizando pectina
}

\author{
Microencapsulation of probiotics by using external ionic gelling pectin
}

\author{
Maria Fernanda da Silveira Cáceres de Menezes $^{1}$, Luiza Zancan Rodrigues², Carlos Pasqualin \\ Cavalheiro $^{1}$, Mariana Araújo Etchepare ${ }^{1}$, Cristiano Ragagnin de Menezes ${ }^{3}$ \\ ${ }^{1}$ Doutoranda em Ciência e Tecnologia de Alimentos, Universidade Federal de Santa Maria, Santa Maria, Brasil \\ mfersilver@hotmail.com; carlos.cavalheiro@mail.ufsm.br; marianaaetchepare@hotmail.com \\ ${ }^{2}$ Graduanda de Tecnologia de Alimentos, Universidade Federal de Santa Maria, Santa Maria, Brasil \\ luiza.zanca.r@hotmail.com \\ ${ }^{3}$ Professor Doutor, Universidade Federal de Santa Maria, Santa Maria, Brasil \\ cristiano.ufsm@gmail.com
}

\begin{abstract}
Resumo
O aumento da expectativa de vida mundial tem despertado o interesse dos consumidores por alimentos saudáveis, impulsionando o desenvolvimento de alimentos funcionais contendo probióticos, dos quais destacam-se os gêneros, Lactobacillus spp, Bifidobacterium spp e Enterococcus spp, conhecidos por realizar efeitos benéficos no cólon. Diversas técnicas de microencapsulação e materiais de revestimento tem sido exploradas, a gelificação iônica externa tem demonstrado ser viável na preservação das culturas probióticas. Polímeros naturais tem sido estudados, como a pectina, matéria-prima que pode ser obtida a partir da extração de resíduos da indústria cítrica. As pectinas são classificadas de acordo com o seu grau de metoxilação, o que influencia na sua capacidade de hidratação e formação de gel. Por ser um fibra dietética, a pectina atua como substrato para a microbiota do cólon, estimulando-a. Por estas características, a utilização de pectina como material de revestimento de micropartículas probióticas apresenta-se como uma alternativa para a realização de trabalhos que visem o estudo da produção, caracterização, viabilidade de micropartículas e das culturas in vitro. Esta revisão tem por objetivo apresentar a microencapsulação de probióticos através do método de gelificação iônica externa, assim como abordar os materiais de revestimento de microcápsulas, com ênfase na utilização de pectina.
\end{abstract}

Palavras-chave: Probióticos. Microencapsulação. Pectina. Gelificação iônica externa.

\begin{abstract}
The increase in global life expectancy has aroused the interest of consumers for heal thy food, driving the development of functional foods containing probiotics, of which stand out genera, Lactobacillus spp. Bifidobacterium spp and Enterococcus spp, known to carry beneficial effects in the colon. Various microencapsulation techniques and coating materials have been explored, the external ionic gelation has proved to be viable preservation of the probiotics cultures. Natural polymers have been studied, such as pectin, raw material can be obtained from the citrus industry waste extraction. Pectins are classified according to their degree of methoxylation, which influences its hydration capacity and gel formation. As a dietary fiber, pectin acts as a substrate for the microflora of the colon, stimulating it. For these characteristics, the use of pectin as a coating material microparticles probiotic is presented as an alternative for carrying out works aimed to study the production, characterization, and Microparticles feasibility of in vitro cultures. This review aims to present microencapsulation of probiotics through external ionic gelation method, as well as address the microcapsules coating materials, with emphasis on the use of pectin.
\end{abstract}

Keywords: Probiotics. Microencapsulation. Pectin. External ionic gelation. 


\section{Introdução}

Os alimentos funcionais tem apresentado um consumo crescente por parte de consumidores preocupados com a qualidade de vida e em manter a saúde, uma vez que estes alimentos apresentam benefícios clínicos comprovados à saúde humana (SINGH et al., 2011). A exemplo disso, os alimentos probióticos são os maiores responsáveis pela expansão deste mercado. No entanto, um dos fatores limitantes da adição de micro-organismos probióticos em uma ampla diversidade de alimentos, consiste na sua viabilidade, ou seja, resistir as condições intrínsecas e extrínsecas ao qual serão expostos, principalmente na forma livre, sem a proteção de microcápsulas. No intuito de ampliar as inovações na indústria de alimentos funcionais, as técnicas de microencapsulação visam desenvolver microcápsulas constituídas de biopolímeros, geralmente polissacarídeos, proteínas, capazes de proteger estes micro-organismos na matriz alimentar, durante a sua vida útil, assim como resistir as condições gástricas, e assim chegar viáveis ao intestino grosso onde proporcionarão benefícios ao consumidor. A técnica de gelificação iônica externa por ser um método brando, não confere riscos a viabilidade microbiana, sendo assim um método bastante utilizado para microencapsular culturas probióticas. A pectina é um polímero natural que pode ser obtida a partir da extração de resíduos da indústria cítrica e do bagaço da maçã. Suas características eletrostáticas e boa capacidade para formar géis conferem à pectina ótimas propriedades para ser utilizada como material de revestimento para formação de microcápsulas probióticas.

\section{Probióticos}

Os probióticos são definidos pela Organização Mundial de Saúde (OMS) como organismo vivos, que quando administrados em quantidades adequadas conferem benefícios para a saúde do hospedeiro, melhorando o equilíbrio da flora microbiana (FAO /WHO, 2002). Neste sentido, os estudos com probióticos tem demonstrado bons resultados no tratamento de desordens intestinais e no sistema imunitário devido a fatores antagônicos que resultam no aumento da resistência contra patógenos (BURGAIN et al., 2011). Deste modo, a utilização de micro-organismos probióticos estimulam a multiplicação das bactérias benéficas reforçando os mecanismos naturais de defesa do hospedeiro em relação ao desenvolvimento de bactérias prejudiciais no intestino grosso (SAAD, 2006).

$\mathrm{O}$ trato gastrointestinal hospeda grande quantidade e diversidade de espécies de bactérias dentre as que colonizam o organismo humano. No estômago e no intestino delgado o ambiente é desfavorável para a colonização e proliferação bacteriana, devido ao peristaltismo intenso nesta porção do intestino, além da ação bactericida do suco gástrico, da bile e da secreção pancreática (STEFE et al., 2008). Estima-se que a população microbiana do cólon seja de $10^{10}$ a $10^{12}$ micro-organismos por grama de conteúdo luminal, entretanto estes números podem variar entre os indivíduos, assim como esta população pode sofrer alterações devido a fatores endógenos e exógenos, como mudanças alimentares, estresse e uso de antibacterianos (STEFE et al., 2008).

No Brasil, a recomendação mais recente para alimentos funcionais contendo probióticos, baseia-se na quantidade diária consumida de micro-organismos viáveis, ou seja, no mínimo $10^{8}$ a $10^{9} \mathrm{UFC} \mathrm{dia}^{-1}$ (BRASIL, 2008).

De acordo com Agrawal e colaboradores (2005) os produtos probióticos representam em média $65 \%$ do mercado mundial de alimentos funcionais e a tendência é a expansão deste mercado de produtos probióticos. A maioria dos alimentos probióticos atuais foram desenvolvidos na área de produtos lácteos, como iogurtes, queijos e sobremesas lácteas e algumas pesquisas no desenvolvimento de outros produtos como chocolates, cereais e sucos (ANAL; SINGH, 2007). Assim destaca-se a necessidade de aplicações destes micro-organismos em outras matrizes alimentares a fim de aumentar as opções para o público consumidor (BURGAIN et al., 2011). No entanto, é relevante a viabilidade das cepas probióticas até o seu local de ação, para usufruir os seus efeitos benéficos (BURGAIN et al., 2011). Os probióticos em geral, e algumas estirpes em particular, têm uma baixa resistência a diferentes condições ambientais, tais como o oxigênio, luz, pH ou temperatura (MUKAI-CORRÊA, 2008; MARTIN et al., 2015).

Os micro-organismos probióticos devem atender a requisitos básicos para assim ser classificados, entre eles: a bactéria deve pertencer a um gênero de origem humana, apresentar resistência ao ambiente ácido estomacal, à bile e às enzimas pancreáticas; apresentar adesão às células da mucosa intestinal; apresentar capacidade de colonização no intestino grosso; produzir substâncias antimicrobianas contra as bactérias patogênicas e ser metabolicamente ativo no intestino (STEFE et al., 2008; SAAD et al., 2011).

\subsection{Gêneros probióticos}

As culturas probióticas de Lactobacillus, Bifidobacterium e Saccharomyces são consideradas GRAS (generally recognized as safe) e a literatura apresenta estudos relevantes, principalmente com os representantes dos gêneros Lactobacillus e Bifidobacterium (STEFE et al., 2008; SAAD et al., 2011). Dentre as culturas probióticas utilizadas em produtos comerciais, com propriedades e efeitos funcionais reconhecidos por meio de estudos clínicos registrados, incluem-se: Lactobacillus casei Shirota, L. johnsonii La1, L. rhamnosus GG (ATCC 53103), L. rhamnosus HN001, L. acidophilus La-5, L. acidophilus NCFB 1478, L. reuteri ATCC 55730, L.casei DN-114001, Bifidobacterium 
animalis Bb12, B. animalis DN173 010, B. animalis subsp. lactis HN019, B. infantis 35264 e Saccharomyces cerevisae (boulardii) (STEFE et al., 2008; SAAD et al., 2011).

\section{Mecanismo de ação de bactérias probió- ticas}

O mecanismo de ação de bactérias probióticas ainda não são totalmente conhecidos, entretanto, há evidências de que os micro-organismos probióticos têm o potencial para ser benéficos à saúde humana (WEICHSELBAUM, 2009).

Os probióticos desempenham um papel terapêutico, através da modulação da imunidade, baixando colesterol, melhorando a tolerância à lactose e prevenindo alguns tipos de câncer (KAILASAPATHY; CHIN, 2000).

Segundo a literatura, os efeitos dos probióticos podem ser classificados em modos de ação: o primeiro está relacionado com a modulação das defesas do hospedeiro que é provavelmente muito importante para a prevenção e tratamento de doenças infecciosas, e também para o tratamento de inflamação intestinal (STEFE et al., 2008; COLLADO et al., 2009). As principais células alvo são geralmente as do epitélio e o sistema imunitário associado as células intestinais. Por fim, a interação entre probióticos e de acolhimento do imunitário células de adesão pode ser a cascata de sinalização de disparo levando a modulação imune (CORTHESY et al., 2007).

O segundo mecanismo de ação pode ser descrito por um efeito direto sobre outros micro-organismos que podem ser comensais ou patogênicos. Neste caso, o tratamento consiste no restabelecimento do equilíbrio microbiano no intestino. Os probióticos têm a capacidade de ser competitivos com agentes patogênicos e, portanto, permitem que estes se alojem e tentem aderir nas células do intestino (STEFE et al., 2008; TUOMOLA et al., 1999).

Apesar dos mecanismos de ação dos micro-organismos probióticos não ser totalmente conhecidos, os aqui apresentados são comumente citados na literatura científica (OELSCHLAEGER, 2010).

\section{Simbióticos}

O termo simbiótico, em resumo, consiste em uma combinação de efeitos positivos causados por probióticos e prebióticos. Os produtos funcionais disponíveis no mercado que apresentam influência benéfica à microflora intestinal são geralmente compostos por probióticos e/ ou prebióticos ou simbióticos quando existir a presença dos dois (STEFE et al., 2008).

Os probióticos já foram apresentados na seção anterior, já os prebióticos podem ser definidos como "ingredientes alimentares não digeríveis" ou "carboidratos não digeríveis" que, quando consumido em quantidades suficientes, estimulam seletivamente o crescimento e/ou atividade de um ou mais micro-organismos no cólon, resultando em benefícios para a saúde do hospedeiro. Os prebióticos têm potencial para melhorar a viabilidade do probiótico e sua vitalidade, assegurando a sua sobrevivência no trato gastrointestinal e posterior fixação e crescimento no intestino (BURGAIN et al., 2011).

Os prebióticos mais utilizados são inulina e fruto-oligossacarídeos (FOS) os quais são considerados fibras solúveis e fermentáveis, as quais não são digeríveis pela alfa-amilase e por enzimas hidrolíticas (sacarase, maltase e isomaltase) na porção superior do trato gastrintestinal, e consequentemente devido à sua resistência contra o ácido gástrico e as enzimas pancreáticas (SAAD et al., 2011). Estas características as tornam prebióticas por não serem absorvidas no intestino delgado, penetrando no intestino grosso e servindo de substrato para as bactérias intestinais e probióticas adicionadas (SAAD et al., 2011).

No Brasil, a legislação recomenda parâmetros baseados na ingestão diária de micro-organismos viáveis e de inulina e FOS que devem ser ingeridos, sendo $10^{8}$ a $10^{9} \mathrm{UFC} / \mathrm{dia}^{-1}$ para probióticos e de FOS e inulina de $3 \mathrm{~g}$ para alimentos sólidos e 1,5g para alimentos líquidos (ANVISA, 2008).

Desse modo, o conceito de simbiótico pode ser definido como "uma mistura de probióticos e prebióticos" que atuam em sinergismo, afetando beneficamente o hospedeiro.

\section{Microencapsulação de probióticos}

A microencapsulação é uma tecnologia que tem sido desenvolvida e aplicada no meio científico e na indústria de alimentos com a função de proteger as culturas probióticas e permitir a sua liberação controlada, pois a viabilidade destes micro-organismos é importante para que estes atinjam o local de ação específico e promovam os benefícios sobre a saúde do consumidor (BURGAIN e al, 2011). A liberação do material encapsulado pode ocorrer por ruptura mecânica, temperatura, pH ou solubilidade do meio, biodegradação ou por difusão (MUKAI-CORRÊA, 2008). Em síntese, a encapsulação de materiais bioativos é um processo físico-químico ou mecânico que consiste em aprisionar essa substância em um polímero ou cápsula, a fim de produzir partículas com diâmetro de poucos nanômetros a alguns milímetros (BURGAIN e al, 2011).

As características ideais de apresentação de um probiótico microencapsulado, de acordo com a literatura, seria na forma de um pó seco, de fácil armazenamento e com uma extensa vida de prateleira ou então, um gel úmido com estabilidade a longo prazo (BURGAIN et al., 2011; SIMEONI et al., 2014).

A microencapsulação de bactérias probióticas fornece uma barreira física para resistir a condições ambientais diversas, uma vez que muitos trabalhos apontam que é reduzida a sobrevivência destas bactérias quando 
inoculadas livres nas matrizes em estudo (KAILASAPATHY, 2009).

\subsection{Métodos de microencapsulação}

As técnicas de encapsulação presentes na literatura permitem encapsular ingredientes alimentícios, compostos bioativos, fármacos, no entanto, a escolha do método deve ser planaejada de acordo com a finalidade da microcápsula, com as propriedades físico-químicas do material de revestimento e do material de recheio, assim como o tamanho e o mecanismo de liberação deste composto (JACKSON; LEE, 1991). As metodologias mais usuais envolvem as técnicas de spray drying (secagem por atomização), spray cooling (secagem a frio), gelificação iônica (interna ou externa), liofilização, coacervação simples e complexa (BURGAIN et al., 2011; SIMEONI et al., 2014).

\subsubsection{Gelificação iônica externa interação eletrostá- tica}

A técnica de gelificação iônica ou extrusão é um processo físico para a microencapsulação de bactérias probióticas em polímeros, como alginato, pectina e carragena. Este método consiste em lançar o material, ou seja, uma solução contendo o polímero e, neste caso, a cultura probiótica, através de um bocal de alta pressão, que irá gotejar em uma solução contendo cloreto de cálcio $\left(\mathrm{CaCl}_{2}\right.$, para que ocorra a solidificação por gelatinização iônica. Nesse processo, o cálcio difunde-se para o interior das gotas do polímero (LIU et al., 2002). Assim, quando duas soluções de macromoléculas com cargas opostas são misturadas, pode-se dizer que estes complexos de polieletrólitos formados são resultado de interações eletrostáticas entre os dois íons (YAO et al., 1997).

A gelificação iônica não causa danos ás células bacterianas, conferindo maior viabilidade aos micro-organismos microencapsulados quando comparados à micro-organismos livres. É uma técnica simples, de baixo custo, mas possui um fator limitante, sua difícil aplicação em escala industrial, devido à formação das microcápsulas ser muito lenta (KRASAEKOOP, BHANDARI, DEETH, 2003). Cápsulas de alginato ou pectina de baixo teor de metoxilação são muito utilizadas como material de revestimento por esta técnica, sendo os íons cálcio o agente de reticulação mais utilizado (MUKAICORRÊA, 2008).

Ventura et al (2015) misturou soluções de pectina e quitosana em faixas de $\mathrm{pH}$ de 3 a 6 , pois formam complexo polieletrolíticos, uma vez que a pectina é carregada negativamente e a quitosana carregado positivamente (VENTURA et al, 2015). A Figura 1, ilustra a técnica de microencapsulação pelo método de gelificação iônica.

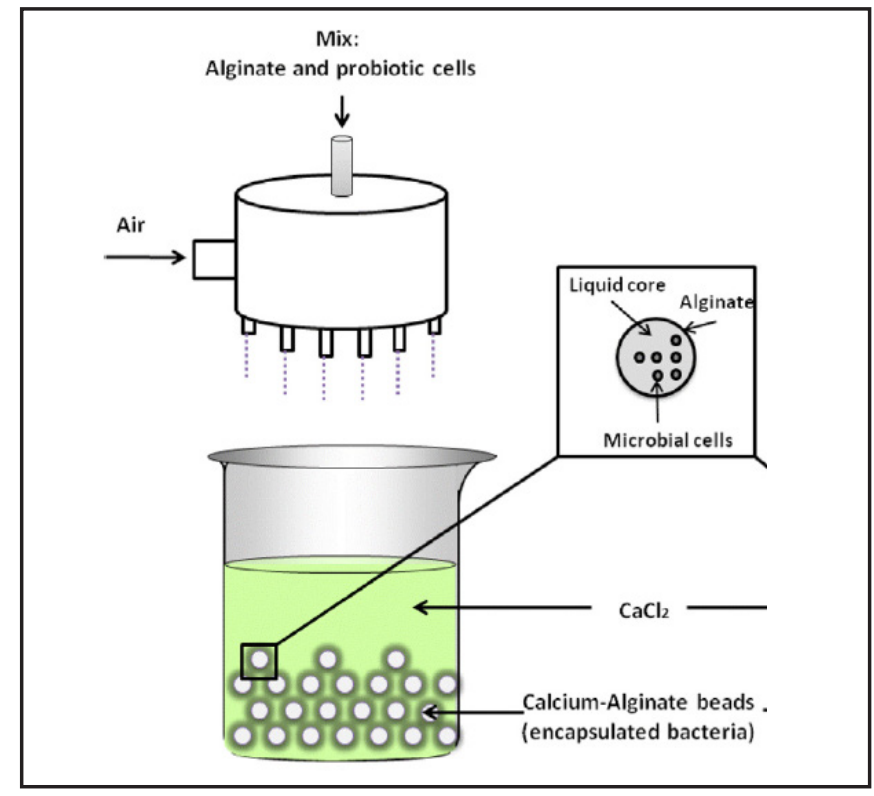

Figura 1 - Representação esquemática do procedimento de gelificação iônica Fonte: BURGAIN et al., 2011

\subsection{Materiais de revestimento de células pro- bióticas}

A expansão do mercado consumidor de alimentos funcionais contendo micro-organismos probióticos tem impulsionado as pesquisas nessa área com o desafio de microencapsular essas culturas através de distintas técnicas e com diferentes materiais de revestimento, bem como, manter essas culturas viáveis nas matrizes alimentares e durante o seu ?shelf-life? para então os consumidores usufruirem dos benefícios à saúde (BURGAIN et al, 2011).

Existem hidrocolóides industrialmente importantes para uso na produção de partículas de gel, a partir de plantas, como amido resistente, pectina e celulose; de algas, como alginato, agar e carragena; de animais, como gelatina (BUREY et al., 2008). Os hidrocolóides são polímeros hidrofílicos que geralmente contêm muitos grupos hidroxilas e podem ser polieletrólitos (BUREY et al., 2008). Em função das origens destes polímeros, naturais ou sintéticos, muitos estão naturalmente presentes nos alimentos ou podem ser adicionados para controlar as propriedades funcionais dos materiais (BUREY et al., 2008).

O amido resistente não é digerido pelas enzimas pancreáticas (amilases) no intestino delgado, chegando ao cólon, onde vai ser fermentado (ANAL; SINGH, 2007). Em função da sua funcionalidade prebiótica, o amido resistente pode ser usado pelos micro-organismos probióticos no intestino grosso e ainda, outra característica relevante deste revestimento, é que o amido resistente apresenta uma superfície ideal, compostas pelos grânulos de amido, para a aderência das células probióticas (ANAL; SINGH, 2007). Em função do baixo custo e alta disponibilidade, o amido tem sido bastante estudado misturado com outras substâncias para melhorar suas 
características (ROSENTHAL et al., 2008).

Enquanto que, o alginato é um carboidrato extraído de algas (Macrocystispyrifera), inodoro, insípido, bastante hidrossolúvel à temperatura de $70^{\circ} \mathrm{C}$, formando uma solução coloidal viscosa (ROSENTHAL et al., 2008). O alginato possui habilidade para a formação de géis fortes pela reação de reticulação com o cálcio, quando utiliza-se cloreto de cálcio $\left(\mathrm{CaCl}_{2}\right)$, assim melhorando as propriedades do revestimento (ROSENTHAL et al., 2008). O alginato de cálcio é um dos polímeros preferidos para a encapsulação de probióticos devido à sua simplicidade, baixo custo, não-toxicidade e biocompatibilidade e (BURGAIN et al., 2011).

A fim de avaliar o comportamento de outros materiais de revestimento de probióticos, Laurenti e Garcia (2013) encapsularam o probiótico Saccharomyces cerevisiae pelo método de imobilização em cubos de ágar-ágar, em diferentes gomas comerciais e mucilagens, com o objetivo de proporcionar liberação controlada do micro-organismo durante a simulação gastrointestinal in vitro. Foram utilizados os seguintes materiais encapsulantes: ágar-ágar, alginato, iota-carragena, goma arábica, taro, inhame, linhaça e quiabo (LAURENTI; GARCIA; 2013). Durante a simulação, foi realizada a contagem da levedura liberada das diferentes matrizes e a viabilidade do probiótico não encapsulado. Os tratamentos apresentaram a seguinte ordem crescente de liberação da levedura: quiabo < linhaça < alginato < inhame < goma arábica < iota-carragena $<$ ágar-ágar $<$ taro. Todos os materiais encapsulantes conferiram proteção física à levedura, no entanto, a mucilagem de quiabo demonstrou ser um material encapsulante alternativo natural mais eficiente do que as gomas comumente usadas no mercado (LAURENTI; GARCIA; 2013).

A combinação de polímeros também está presente na literatura como alternativas para melhorar as características dos filmes para microencapsular compostos bioativos. Um exemplo, é a mistura de alginato e quitosana, formando um complexo por interação eletrostática, onde a quitosana é considerada uma matriz de liberação controlada, uma vez que forma gel em pH baixo, atrasando a liberação do composto bioativo (ROSENTHAL et al., 2008).

A gelatina é uma proteína que pode ser obtida a partir da hidrólise enzimática do colágeno; apresenta grande permeabilidade ao vapor de água por possuir caráter hidrofílico. Quando preparada com glicerina ou sorbitol, resulta em um revestimento flexível, resistente e impermeável ao oxigênio (ROSENTHAL et al., 2008).

Os materiais hidrocolóides naturais tem apresentado um crescente interesse por uma grande parte de pesquisadores, em função da formação de partículas de gel encapsuladas e o controle de textura no interior dos alimentos, produtos farmacêuticos, probióticos, médicos, e cosméticos (BUREY et al., 2008).

\subsubsection{Pectina}

\subsubsection{Definição}

As pectinas consistem em complexos de polissacarídeos estruturais presentes em vários tecidos vegetais, apresentam caráter hidrofílico, devido à presença de grupos polares, e por isso, tem a propriedade de envolver grande quantidade de água, produzindo uma solução viscosa. É amplamente utilizada na indústria de alimentos, principalmente devido sua capacidade de formar géis, e ainda são utilizadas como agentes espessantes, texturizantes, emulsificantes ou estabilizantes.

Naturalmente, a pectina está associada à celulose, hemicelulose e lignina, sendo designada enquanto nesta forma de protopectina, podendo ser obtida comercialmente por extração aquosa de material péctico da maioria dos frutos cítricos e em maçãs (BOBBIO; BOBBIO, 2001; MUKAI-CORRÊA, 2008; CANTERI et al., 2012). A importância da pectina na tecnologia e no processamento de alimentos está associada à sua função de conferir firmeza, retenção de sabor e aroma, bem como a sua função como hidrocolóide na dispersão e estabilização de diversas emulsões (PAIVA et al., 2009). A formação de gel é a principal característica funcional da pectina e depende essencialmente das características do meio: $\mathrm{pH}$, teores de sólidos solúveis e cátions divalentes, além de depender dos níveis de pectinas e do seu grau de metoxilação (PAIVA et al., 2009).

\subsubsection{Estrutura química, características e interações da pectina}

A pectina é um polissacarídeo com cerca de 150 a 500 unidades de ácidos galacturônicos (Figura 2) parcialmente estereficados com grupos metoxilícos, unidos por ligações glicosídicas $\alpha$ - 1,4 (KOBLITZ, 2010; MUZZARELLI et al., 2012; COELHO, 2008) que formam cadeias lineares interrompidas pela presença do açúcar ramnose a intervalos periódicos, sendo normalmente classificada de acordo com seu grau de esterificação (MUKAI-CORRÊA, 2008; MUZZARELLI et al., 2012). Usualmente são classificadas em pectinas de baixo e alto teor de esterificação, onde o grau de esterificação é a porcentagem de ácidos galacturônicos que são metilesterificados (MUKAI-CORRÊA, 2008; MUZZARELLI et al., 2012), ou seja, a razão entre o ácido galacturônico esterificado e não esterificado irá determinar o comportamento da pectina nas aplicações alimentares (MUZZARELLI et al., 2012). Os metil ésteres formados ocupam um espaço similar, mas são mais hidrofóbicos e consequentemente têm um efeito diferente na estruturação da água. A pectina é um poliácido e seu pkA é de cerca de 2,9, apresentando pouca carga negativa em $\mathrm{pH}$ baixo e alta em $\mathrm{pHs}$ elevados, possui boa solubilidade, no entanto, necessita ser dispersa em água aquecida com temperatura acima de $60^{\circ} \mathrm{C}$ (MUKAICORREA, 2008). 
A associação da pectina (poliânion) com um policátion forma produtos insolúveis. Geralmente, as pectinas não possuem estruturas exatas, a molécula não adota uma conformação reta em solução, mas ocorre de forma estendida e flexível.

A gelificação da pectina de baixo teor de metilação (BTM), quando a pectina contém $50 \%$ ou menos dos seus grupos carboxílicos esterificados, ocorre por meio da formação de ligações entre íons carboxílicos da pectina e íons bivalentes, geralmente cálcio ou outro metal bi ou trivalente, ou tetravalentes para alto teor, que atuam como ligantes entre as cadeias de pectina e ficarão ligados covalentemente a grupos OH (BOBBIO; BOBBIO, 2001; KOBLITZ, 2010; CANTERI et al., 2012). Elas envolvem ligações quelantes intermoleculares do cátion, induzindo a formação de macromoléculas agregadas.

A formação da rede de gel com íons cálcio, segue o modelo denominado "eggbox", ou seja, o modelo da caixa de ovos, sugerido da mesma forma que os géis de alginato. Os géis são geralmente formados em concentrações maiores que $1 \%$ e a proporção de cálcio mais adotada, seguindo alguns autores, é de 0,1 a 0,5\% do peso do gel, sendo essa formação prejudicada na presença de pH muito ácido. Os géis formados são termoreversíveis, entre $\mathrm{pH}$ 3,0 e 4,0. Essa redução pode ocorrer porque dois grupos carboxilados são associados à água antes dos íons cálcio formarem as ligações salinas, fazendo a zona de junção. A força do gel aumenta à medida que eleva-se a concentração de cálcio, mas é reduzida com o aumento da temperatura e da acidez $(\mathrm{pH}<3)$.

As pectinas de baixo teor de metoxilação também gelificam na ausência de cálcio pela formação de associações entre cadeias em baixa temperatura $\left(\sim 10^{\circ} \mathrm{C}\right)$ para formarem géis transparentes. As composições e propriedades das pectinas variam com a matéria-prima utilizada nos processos de extração e tratamentos realizados (MUKAI-CORRÊA, 2008).

As características eletrostáticas e a formação de géis conferem à pectina ótimas propriedades para ser utilizada como material de revestimento para formação de microcápsulas. Alguns aspectos funcionais da pectina ligados à saúde têm sido estudados e indicam que ela é hidrolizada no trato gastrointestinal, produzindo substâncias não calóricas, interagindo com o colesterol na regulação da homeostase do colesterol hepático e no metabolismo de lipoproteínas (MUZZARELLI et al., 2012).

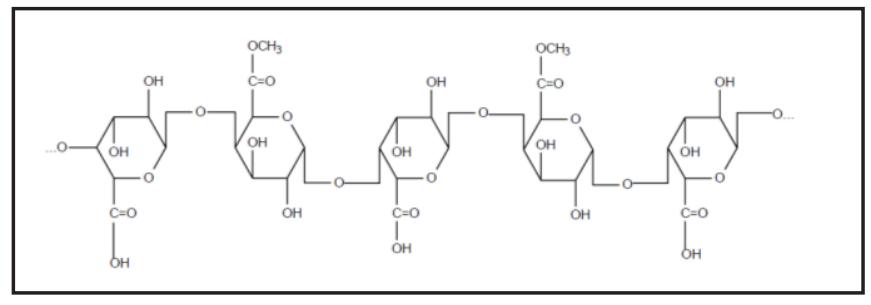

Figura 2 - Estrutura geral da pectina Fonte: BOBBIO, 1989
5.2.1.3 Propriedades físicas e mecanismos de formação de géis

As propriedades físicas das substâncias pécticas são atribuídas principalmente à sua estrutura e composição química. Neste sentido o grau de metoxilação da pectina e os grupos carboxilas livres (íons carboxilatos) contribuem para o mecanismo de geleificação, sendo a relação [COOCH3:COO-] o principal indicador das suas propriedades funcionais (BOBBIO; BOBBIO, 2001; PAIVA et al., 2009). Géis de pectina originam-se através da formação de ligações cruzadas que formam uma rede cristalina tridimensional onde as moléculas de água e os co-solutos ficam presos em máxima coalescência (BOBBIO; BOBBIO, 2001; PAIVA et al., 2009). Apesar da relevância deste tópico pouco se conhece da estrutura química das pectinas nos diferentes vegetais. Na pectina de alta metoxilação, as zonas de junção são formadas por ligações cruzadas do ácido galacturônico por pontes de hidrogênio e forças hidrofóbicas entre os grupos metil(KOBLITZ, 2010). O abaixamento do $\mathrm{pH}(2,2$ a 3,0) e a elevada concentração de açúcares (> 60\%) facilita este processo, e induz a redução da solvatação da pectina, aumentando a interação entre as suas moléculas (PAIVA et al., 2009). Os grupos carboxilas, particularmente, influenciam na viscosidade e coesividade da solução de pectina, o que por sua vez, depende do grau de esterificação por grupamentos metil deste polímero. Em solução de pectina totalmente esterificada não são observadas mudanças significativas com alterações no $\mathrm{pH}$, portanto à medida que o grau de metoxilação é reduzido a viscosidade torna-se cada vez mais dependente do $\mathrm{pH}$. Aparentemente, os grupamentos carboxilas da pectina de alta metoxilação se ionizam com o aumento do $\mathrm{pH}$. Essa mudança é resultado da repulsão eletrostática entre as cadeias causando maiores interações intermoleculares o que ocasiona aumento na viscosidade e coalescência. Por outro lado, em pectina de baixa metoxilação e em ácidos pécticos a associação entre as moléculas ocorre quando o pH está muito abaixo de 4,0, proporcionando também incremento na viscosidade (PAIVA et al., 2009). Outro importante fator que controla a viscosidade e a geleificação, e por conseguinte, a solubilidade das pectinas, é o seu peso molecular, que varia entre 30.000-70.000 kDa em pectina de frutos cítricos (PAIVA et al., 2009). A solubilidade é um parâmetro fortemente influenciado pelas propriedades físico-químicas da pectina, de modo, esta tende a aumentar com o incremento do grau de metoxilação e com a redução do peso molecular da pectina (KOBLITZ, 2010; PAIVA et al., 2009). Estas características direcionam aplicações industriais e tecnológicas diferenciadas. Os níveis de pectinas também são um fator importante, sendo necessária sua presença em pelo menos $0,1-1 \%$ para que a geleificação ocorra, visto que em quantidades reduzidas, géis frágeis podem ser formados (PAIVA et al., 2009). Por outro lado, em pectinas de baixa metoxilação, a formação do gel envolve 
ligações simultâneas entre íons de cálcio com grupos carboxilas livres (carboxilatos) formando também uma rede cristalina (BOBBIO; BOBBIO, 2001; PAIVA et al., 2009). As propriedades físicas das moléculas de pectina as tornam um ingrediente importante e bastante utilizado pela indústria alimentícia para aumentar a viscosidade de soluções, e principalmente assumindo papel de hidrocolóide na função de dispersante e estabilizante de diversas emulsões de carboidratos e de proteínas em formulações e alimentos naturais (PAIVA et al., 2009).

\subsubsection{Fontes}

As fontes industriais mais importantes de pectinas são bagaço de maçã e a casca de frutas cítricas, no entanto, outras pectinas podem ser produzidas para fins específicos, como por exemplo pectina de beterraba que possui propriedade emulsionante (PAIVA et al., 2009; MUZZARELLI et al., 2012).

\subsubsection{Aplicações}

A pectina industrial promove aumento da viscosidade, atua como coloide estabilizante e protetor de alimentos e bebidas, enquanto que devido aos seus efeitos farmacológicos, integra o grupo dos polissacarídeos não amiláceos, das fibras dietéticas, juntamente com as hemiceluloses, gomas, beta-glucanas (CANTERI et al., 2012). Estudos recentes comprovaram que a pectina pode promover saúde por meio da redução do mau colesterol (LDL) sem alterar o bom colesterol (HDL).

Além do amplo emprego industrial nas áreas de alimentos, farmacêutica e cosmética, a pectina vem sendo utilizada para remover metais tóxicos em soluções aquosas e como agente floculante no tratamento de efluentes, apresentando a vantagem de ser biodegradável e atóxica ao meio ambiente e aos seres humanos (YOKOI et al., 2002).

\section{Conclusões}

A incorporação de probióticos em alimentos apresenta um grande desafio tecnológico, que consiste em manter a viabilidade das bactérias durante as condições de processamento e vida de prateleira do produto. Neste sentido, mais pesquisas devem ser realizadas utilizando a pectina como matriz de revestimento de micropartículas probióticas. Por ser uma matéria-prima de fácil aquisição, com custo acessível, seus estudos devem ser muito bem elucidados para viabilizar a sua aplicação, já que é um biopolímero com ampla versatilidade e com características satisfatórias.

Ainda, no campo da microencapsulação de probióticos, estudos de formação e caracterização de microcápsulas elaboradas com pectina devem ser mais explorados, independente da técnica utilizada, assim como, o estudo do tamanho e resistência da partícula, a sua complexação com outros polímeros polissacarídicos ou proteicos, a formação de multicamadas de revestimentos, a morfologia, a liberação in vitro, entre outros, visto as suas características tecnológicas de aplicação e seus benefícios à saúde.

\section{Agradecimentos}

Os autores agradecem a CAPES pelo apoio.

\section{Referências}

Agrawal, R. (2005). Probiotics: an emerging food supplement with health benefits. Food Biotechnology, 19 (3), 227-246.

Anal, A. K., Singh, H. (2007). Recent advances in microencapsulation of probiotics for industrial applications and targeted delivery. Trends Food Science and Technology 18 (5), 240-251.

Bobbio, F. O.; Bobbio, P. A. Introdução a Química de Alimentos. 2 ${ }^{\mathrm{a}}$ Ed. São Paulo: Varela, 231 p., 1989.

Bobbio, F. O.; Bobbio, P. A. Química do processamento de alimentos. $3^{\text {a }}$ Ed. São Paulo: Varela, 143 p., 2001.

Brasil. Lista de alegações de propriedade funcional aprovadas. Brasília, 2008. Disponível em: www.anvisa.gov.br/alimentos/comissoes/tecno lista alega.htm. Acesso em: 06 de out. de 2014.

Burey, P., et al. (2008). Hydrocolloid Gel Particles: Formation, Characterization, and Application. Critical Reviews in Food Science and Nutrition, 48, 361-377.

Burgain, J., et al. (2011). Encapsulation of probiotic living cells: From laboratory scale to industrial applications. Journal of Food Engineering, 104, 467-483.

Canteri, M. H. G. et al. (2012). Pectina: da matériaprima ao produto final. Polímeros, 22 (2), 149-157.

Coelho, M. T. (2008). Pectina: Características e aplicações em alimentos. In: Disciplina de Seminário de Alimentos. Universidade Federal de Pelotas, Pelotas, RS.

Collado, M. C., et al. (2009). The impact of probiotic on gut health. Current Drug Metabolism, 10 (1), 68-78.

Corthesy, B., et al. (2007). Cross talk between probiotic bacteria and the host immune system. Journal of Nutrition, 137 (3), 781S-790S.

FAO. Food and Agriculture Organization of the 
United Nations (2002). Guidelines for the Evaluation of Probiotics in Food. London, Ontario, Canada.

Jackson, L. S.; Lee, K. (1991). Microencapsulation and Food Industry. LWT-Food Science and Technology 24, (4), 289-297.

Kailasapathy, K.; Chin, J. C. (2000). Survival and therapeutic potential of probiotics organisms with reference to Lactobacillus acidophilus and Bifidobacterium spp. Immunology e Cell Biology, 78, 80-88.

Kailasapathy, K., (2009). Encapsulation technologies for functional foods and nutraceutical product development. CAB Reviews: Perspectives in Agriculture, Veterinary Science, Nutrition and Natural Resources, 4 (6).

Koblitz, M. G. B. Bioquímica de alimentos: teoria e aplicações práticas. Rio de Janeiro: Guanabara Koogan, 2010, 242 p.

Krasaekoopt, W., Bhandari, B., Deeth, H., (2003). Evaluation of encapsulation techniques of probiotics for yoghurt. International Dairy Journal 13 (1), 3-13.

Laurenti, E.; Garcia, S. (2013). Eficiência de materiais encapsulantes naturais e comerciais na liberação controlada de probiótico encapsulado. Brazilian Journal of Food Technology, 16 (2), 107-115.

Liu, X. D. et al. (2012). Characterization of structure and diffusion behaviour of ca-alginate beads prepared with external or internal calcium sources. Journal of microencapsulation, 19 (6), 775 - 782.

Martin, M. J. et al. (2015). Microencapsulation of bacteria: A review of different technologies and their impact on the probiotic effects. Innovative Food Science and Emerging Technologies 27, 15-25.

Mukai Corrêa, R. Produção de micropartículas por gelificação iônica para alimentação de larvas de peixe: Estudos em Sistema-Modelo com inclusão de micropartículas lipídicas ou emulsão lipídica e Testes in vivo. 2008. 177 p. Tese (Doutorado em Alimentos e Nutrição) - Universidade Estadual de Campinas, Campinas, 2008.

Muzzarelli, R. A. A. et al. (2012). Current views on fungal chitin/chitosan, human chitinases, food preservation, glucans, pectins and inulin: A tribute to Henri Braconnot, precursor of the carbohydrate polymers science, on the chitin bicentennial. Carbohydrate Polymers, 87, 995- 1012.

Oelschlaeger, T. A. (2010). Mechanisms of probiotic actions - a review. International Journal of Medical Microbiology, 300 (1), 57-62.

Paiva, E. P. et al. (2009). Pectina: Propriedades Químicas e Importância sobre Estrutura da Parede
Celular de Frutos Durante o Processo De Maturação. In: Propiedades químicas de las pectinas. Revista Iberoamericana de Polímero, 10, 4, 196-211.

Rosenthal, A. Tecnologia de Alimentos e Inovação: Tendências e Perspectivas. Brasília: Embrapa Informação Tecnológica, 2008, 193 p.

Saad, S. M. I. Probióticos e prebióticos em alimentos: fundamentos e aplicações tecnológicas. São Paulo: Varela, 2011, 668 p.

Saad, S. M. I., (2006). Probióticos e prebióticos: o estado da arte. Brazilian Journal of Pharmaceutical Sciences 42 (1), 1-16.

Simeoni, C. P. et al. (2014). Microencapsulação de probióticos: inovação tecnológica na indústria de alimentos. Revista Eletrônica em Gestão, Educação e Tecnologia Ambiental, 18, ed. esp. mai, 66-75.

Singh, K. et al. (2011). Probiotics: a review. Asian Pacific Journal of Tropical Biomedicine, S287-S290.

Stefe, C. A. et al. (2008). Probióticos, prebióticos e simbióticos: artigo de revisão. Saúde \& Ambiente em Revista, 3 (1), 16-33.

Tuomola, E. M., et al. (1999). The effect of probiotic bactéria on the adhesion of pathogens to human intestinal mucus. FEMS Immunology and Medical Microbiology 26 (2), 137-142.

Ventura, I; Bianco-Peled, H. (2015). Smallangle $X$-ray scattering study on pectinchitosan mixedsolutions and thermoreversible gels. Carbohydrate Polymers, 123, 122-129.

Weichselbaum, E. (2009). Probiotics and health: a review of the evidence. Nutrition Bulletin, 34 (4), 340-373.

Yokoi, H. et al. (2002). Flocculation properties of pectin in various suspensions. Bioresource Technology, 84, 287-290.

Yao, K. D., Tu, H., Cheng, F., Zhang, J. W., \& Liu, J. (1997). pH-sensitivity of the swelling of a chitosan-pectin polyelectrolyte complex. Die Angewandte Makromolekulare Chemie, 245, 63-72. 